\title{
The Optimal Location of Ambulance Stations in a Regional Area: The Case of Mackay
}

\author{
M. Dzator ${ }^{a}$ and J. Dzator ${ }^{b}$ \\ ${ }^{a}$ Central Queensland University, Mackay; ${ }^{b}$ The University of Newcastle, NSW \\ Email:1m.dzator@,cqu.edu.au
}

\begin{abstract}
The provision of efficient and effective emergency service such as ambulance service is a task faced by most cities and major regional centres. The emergency medical service is very necessary and plays a vital role in reducing death or serious complication from life threatening health incident. Over the years, there have been several major initiatives to improve the access to and quality of emergency care in Queensland. In 2009-2010, public hospital Emergency Departments (ED) in Australia covered about 7.4 million emergency cases of which there were over 3 million ambulance incidents.
\end{abstract}

Mackay is a regional city in Queensland, Australia's east coast. The Mackay Metropolitan which comprises of 24 suburbs is prone to natural disasters such as cyclones and flood. The Mackay region depends highly on emergency services especially during disasters. The current ambulance locations in the Mackay Local Ambulance Service Network (LASN) are significantly underperforming with regard to not meeting the target response time according to Queensland 2014 ambulance report. Early response to emergency calls is important and crucial for human survival. The response time is a function of the distance between the emergency facility and emergency demand. It is therefore important to locate emergency facility such that the distance to be travelled by an ambulance in response to emergency call is minimized.

The $p$-median problem finds the location of $p$ facilities to minimize the demand weighted average or total distance between demand or population and their closest facility. The objective of this study is to discuss the importance of the application of the $p$-median model to locate emergency stations. We compare existing ambulance stations with the optimal solutions proposed by the $p$-median location models in the Mackay region. We determine the cost of assessing the facilities that are located using the $p$-median model and showed the cost saving of the model when optimal locations are compared with locations when facilities are added to the existing ambulance locations optimally.

Keywords: Optimal, emergency, ambulance, cost 


\section{INTRODUCTION}

The accessibility to ambulances during emergency situations is an important aspect of health care delivery in most cities and major regional centres. It is vital for health care to be provided within a short time during any life-threatening emergency situations. There have been several major initiatives to improve the access to and quality of emergency care in Queensland. In 2009 and 2010, public hospital Emergency Departments (ED) in Australia dealt with about 7.4 million services. This is equal to 331 services per 1000 people. In Queensland the utilization rate is 350 services per 1000 people which is above the national average. People in regional areas in 2007-2008 were 1.7 times more likely to use Emergency Departments than the major cities. In Queensland 512 per 1000 used the Emergency Departments over the same period. The number of ambulance incidents recorded in Australia in 2009 and 2010 is over 3 million while the ambulance utilization rate in Queensland is 169 incidents per 1000 people. The demand for ambulance is constantly rising in Queensland for the period of ten years from 2000 to 2010 (Toloo et al.; 2011).

Mackay is a regional city in Queensland, on Australia's east coast. The Mackay Metropolitan area has 24 suburbs with the population of 76,069 reported in 2011. Mackay region is prone to natural disasters such as cyclones as evidenced by cyclone Debbie in the area just recently. It is therefore crucial for proper location and adequate number of emergency facilities for effective response during those natural disasters. The latest report for the period of July 2016 to March 2017 for the Mackay region indicates that $50 \%$ of the life threatening emergencies are responded within 8.3 minutes while $90 \%$ of the life threatening events are responded within 18 minutes which is higher than the state average of 16.8 minutes. There have been 90 ambulance incidents for which 73 of them have been transported by road. This is about $81 \%$ of the incidents which were transported by road for 9 months (July 2016 to March 2017). The average current cost of ambulance usage in Queensland per incident is \$645 as reported in the 2013-14 ambulance service performance report.

The major problem is to determine the optimal location of the ambulances for effective health care delivery. The $p$-median problem finds the location of $p$ facilities to minimize the demand weighted average or total distance between demand or population and their closest facility. The objective of this study is to discuss the importance of the application of the $p$-median model to locate ambulance stations in Mackay. We consider Mackay for the study because apart from Queensland ambulance report, the study on Mackay ambulance location is very limited. We also learnt from 2013-14 ambulance service performance report that Mackay LASN is under performing so we are motivated to conduct a research on Mackay to investigate that claim. We compare existing ambulance stations with the optimal solutions proposed by the $p$ median location models in the Mackay region. We determine the cost of assessing the facilities that are located using the $p$-median model. We compare the optimal locations with the locations resulting from adding facilities optimally to the existing ambulance locations. The paper is organized as follows. We briefly discuss the characteristics of ambulance locations in rural and urban areas in Section 2. In Section 3, we present the mathematical formulations of the $p$-median problem. We also discuss the $p$-median problem in terms of distance and transportation cost in Section 3. We discuss Mackay metropolitan area and present Mackay data in Section 4. Computational results obtained from Mackay data is presented in Section 5 and conclusion in Section 6.

\section{AMBULANCE LOCATIONS IN RURAL AND URBAN AREAS}

The ambulance care provided by rural emergency care is not different from the care provided by urban and suburban emergency workers. The operational mode is however difficult in the rural settings than the urban areas. The challenges that are faced in the rural areas include; the distance from the patient to an essential service and the level of infrastructure etc. Mackay metropolitan is surrounded by a number towns and remote mining areas hence the importance of the discussion on rural ambulance location. Moreover, a study by Busko (2008) stated that emergency delivery for population smaller than 250, 000 have not been reliable which is one of the major problems that are encountered in rural areas. Mackay with a population of 76,069 falls into this category. We can therefore state that the services in the major cities in Australia are more reliable than the regional areas (see Hamilton et al., 2010 and Leeuwenburg and Hall, 2015).

A study by Barneveld et al. (2015) indicated that a reduction of one ambulance busy or not available in rural area is more noticeable in rural areas than in an urban area because of the limited number of ambulances in rural areas. The ambulance coverage in urban areas is uniform while it is not uniform in rural areas as population in rural area is not uniformly distributed. There is also greater area to be served in the rural or semi-urban area therefore the average response time is longer in the rural than the urban area. The road conditions and longer distances to be travelled in rural areas also contribute to longer response time. There 
are number of studies (Goodman et al.; 1997) that have stated that increased demand and better managed care occur in urban areas. In terms of cost, the per capita cost of providing ambulance in rural areas is general higher compare to urban densely populated areas.

The models to be used to locate facilities in less densely populated areas such as regional or rural areas are debatable. Chanta et al. (2014) stated that traditional covering models do not favour rural or semi-rural areas or less densely populated areas. They stated that using covering models will result in longer response times for patients in less densely populated areas. A study by Lee stated that the ambulance locations in rural or semi urban areas are designed based on distance from a fixed service (Lee; 2014).

In Australia, the paramedics who work in the rural areas in Australia experience stress according to the study by Hamilton et al. (2010). Pyper and Paterson (2016) also stated that rural and regional ambulance personnel in Australia experience high levels of fatigue and emotional trauma at work. The paramedics at the rural areas have to transfer a large proportion patient from small rural health facilities to urban medical care. There is therefore larger workload for Australian rural paramedic as compared to the paramedics in the urban areas.

\section{THE $P$-MEDIAN PROBLEM}

The objective of the $p$-median problem is to find the locations of $p$ facilities to minimize the demand weighted total cost between each demand node and the nearest facility. For the $p$-median problem the cost of serving demands at node $i$ is the product of the demand at node $i$ and the distance between demand node $i$ and the nearest facility to node $i$. The demand is proportional to the population at node $i$. The $p$-median problem in general is concern with the performance of the whole network instead of trying to solve only a particular problem in the network.

$$
\begin{aligned}
& I=\text { the set of demand nodes indexed by } i \\
& J=\text { the set of candidate facility locations, indexed by } j \\
& p=\text { the number of servers to be deployed or facilities to be located } \\
& a_{i}=\text { the population at the demand node } i
\end{aligned}
$$

subject to

$$
\begin{aligned}
& \sum_{j \in J} Y_{i j}=1, \forall i \in I \\
& \sum_{j \in J} X_{j}=p \\
& \quad Y_{i j} \leq X_{j}, \quad \forall i \in I, j \in J \\
& Y_{i j} \in\{0,1\}, \forall i \in I, j \in J \\
& \quad X_{j} \in\{0,1\}, \quad \forall j \in J
\end{aligned}
$$

The objective (1) is to minimize the total cost from customers or clients to their nearest facility. Constraint (2) shows that the demand of each customer or client must be met. From constraint (3), the number of facilities to be located is $p$. Constraint (4) shows that customers must be supplied from open facility. Constraints (5) and (6) present the problem as a binary integer programming. The above formulation assumes that the potential facility sites are nodes on the network. Hakimi (1964) showed that allowing facilities to be located on the arcs of the network instead of the nodes would not reduce total travel cost.

A number of authors have used the $p$-median model to locate or relocate emergency facilities. These include Berlin et al. (1976); Carson and Batta (1990); McAleer and Naqvi (1994) Serra and Marianov (1998); Caccetta and Dzator (2001, 2005); Dzator and Dzator (2013, 2015). Recently, Dzator and Dzator (2016) relate the use of $p$-median problem to locate facilities to development. 


\subsection{The $p$-median problem and the cost of accessing facilities}

The $p$-median problem is simply to minimize the transportation cost between the facility and the allocated customers. We may state the problem basically as a combinatorial optimization problem as:

$$
\min _{F \subseteq J}\left\{\sum_{i \in I} \min _{j \in F} d_{i j}:|F|=p\right\} \text { (Using the same notation) }
$$

The transportation cost can also be referred to as the connection cost between a customer or patient and the facility. The cost depends on the number of facilities that is accessible and the travel distance. According to Daberkow and King (1977) emergency ambulance service is considered to be price and income inelastic. That is emergency service is an essential service that would be acquired at almost any cost however, the closer the facility is to the customer or patient the better it is for the provider and the patient. The cost of accessing the facility increases as the distance between the facility and the customer increases. We assume that customers or patients will only use their closest facility.

In the siting of emergency facilities the facilities are located such that customers or patients are assigned to the facilities to minimize the total cost. The connection cost from the facility to the demand or patients is directly related to the distance between the facility and the patients. That is the longer the distance the higher the cost in accessing a facility assuming that all other variables in relations to the facilities located are the same. If we assume that the only variable cost in using the facilities is the transportation cost then the cost saving is related to how long it takes to get access to the facilities. We also assume that each potential facility has the same fixed cost for locating a facility and the facility do not have capacities on the demand that they can serve.

For the $p$-median problem as stated by Daskin and Maas (2015) the demand weighted cost or distance decreases with the addition of each subsequent facility. If the previous facilities that are located is optimal then adding the next facility at any potential site that does not have a facility will decrease the demand weighted total cost or distance.

The total cost is determined by summing the weighted distances from each node to each of the proposed facilities. The objective of facility location problems is to locate facility to minimize the total setup cost and the total transportation cost. For this paper we will consider only transportation cost because we assume that the cost of locating the facilities is the same. For uniform setup cost minimizing the transportation cost is the way to effectively locate facilities.

Caccetta and Dzator (2005) stated that the response time depends on the distance between emergency facilities and the patients. The solutions to the $p$-median are efficient since they bring the emergency facilities into closer proximity of the users. This will result in the reduction of the response time if we assume that all other variables remain constant. The $p$-median model also considers everyone in the community when facilities are located unlike other basic location models such as the $p$-centre model and the maximal covering location models (MCLP) which aims at maximizing the population that is covered or served. The $p$-median model therefore evaluates the performance of the whole network instead of just solving a particular problem within the network.

\section{MACKAY METROPOLITAN AREA}

The Mackay metropolitan comprises of 24 suburbs and it has two ambulance stations located at Mackay City and North Mackay. There is one major public hospital in Mackay. We will discuss below how we obtained the data for the study.

\section{Data}

For this study the distance matrix from node to node is determined by distance data developed by Travelmate Company. This distance is the road network among the various suburbs in the Mackay metropolitan area. Hence the distance values are the shortest road travel distances (equivalent to distance on a road map) between the origin and the destination.

We weighted the distance by taking into consideration only the population of the origin suburb since we can also weigh by considering the nature of the road. The fact is that the better the road network the easier it is for a vehicle to move from one suburb to another. The weighted distance is thus the product of the population at the origin suburb and the distance between the origin suburb and the destination suburb. We note that the larger the population the larger the weight. This weighted distance is calculated for each of the twenty-four suburbs in the Mackay Metropolitan region. This calculation is done by noting the distance from a suburb to 
all other suburbs and each value is multiplied by the weight of the origin suburb. This is repeated for every suburb and values are recorded as a column matrix representing Mackay Metropolitan area. The population for the suburbs which was used for the weight for each node ranges from 38 for a suburb of Cremorne to 9372 which corresponds to Andergrove and this shown in Table 1 below. The minimum weighted distance for the Mackay Metropolitan area is $76 \mathrm{~km}$ and the maximum value is $178,068 \mathrm{~km}$.

Table 1. Names of suburbs in Mackay Metropolitan Area and their Population from 2011 Census Data

\begin{tabular}{|l|l|l|l|l|l|}
\hline Node & Suburb & Population & Node & Suburb & Population \\
\hline $1^{*}$ & Mackay City & 4072 & 13 & Erakala & 351 \\
\hline 2 & East Mackay & 3636 & 14 & Glenella (with Foulden) & 4633 \\
\hline 3 & West Mackay & 6507 & 15 & Mackay Harbour & 733 \\
\hline $4^{*}$ & North Mackay & 6597 & 16 & Mount Pleasant & 4751 \\
\hline 5 & South Mackay & 7416 & 17 & Ooralea & 2601 \\
\hline 6 & Andergrove & 9372 & 18 & Paget & 360 \\
\hline 7 & Beaconsfield & 4934 & 19 & Racecourse & 242 \\
\hline 8 & Blacks Beach & 2871 & 20 & Richmond & 505 \\
\hline 9 & Bucasia & 4257 & 21 & Rural View (with Nindaroo) & 3324 \\
\hline 10 & Cremorne & 38 & 22 & Shoal Point & 1086 \\
\hline 11 & Dolphin Heads & 398 & 23 & Slade Point & 3859 \\
\hline 12 & Eimeo & 3309 & 24 & Te Kowai & 217 \\
\hline
\end{tabular}

\section{COMPUTATIONAL RESULTS}

We used the SITATION software (Daskin; 1995) to determine the results for the existing locations and the optimal locations. The first two existing locations are known so we determined their objective values using the SITATION software. Facilities are then added optimally to existing locations using the SITATION software and we noted the objective value for the locations. The optimal locations were determined by the implementation of the Lagrangian relaxation in the SITATION software (Daskin; 1995).

Table 2. The Existing Location and the $P$-Median Locations with Total Population Weighted Distance (TPWD)

\begin{tabular}{|l|l|l|}
\hline Number of Facilities & Existing Locations - TPWD & Optimal Location - TPWD \\
\hline 2 & $\{1,4\}-855120$ & $\{10,22\}-7106$ \\
\hline 3 & $\{1,4,10\}-7600$ & $\{8,10,22\}-6498$ \\
\hline 4 & $\{1,4,10,22\}-6919$ & $\{8,10,11,22\}-5928$ \\
\hline 5 & $\{1,4,8,10,22\}-6308$ & $\{8,9,10,11,22\}-5396$ \\
\hline 6 & $\{1,4,8,10,11,22\}-5738$ & $\{8,9,10,11,12,22\}-4864$ \\
\hline 7 & $\{1,4,8,9,10,11,22\}-5206$ & $\{8,9,10,11,12,22,24\}-4370$ \\
\hline
\end{tabular}

Table 3. Distance Cost for Existing Location (EL), Optimal Location (OL) and Average Cost Per Person

\begin{tabular}{|l|l|l|l|l|}
\hline Number of Facilities & EL Cost & OL Cost & Average Cost - EL & Average Cost - OL \\
\hline 2 & 855120 & 7106 & 11.241 & 0.093 \\
\hline 3 & 7600 & 6498 & 0.100 & 0.085 \\
\hline 4 & 6916 & 5928 & 0.091 & 0.078 \\
\hline 5 & 6308 & 5396 & 0.083 & 0.071 \\
\hline 6 & 5738 & 4864 & 0.075 & 0.064 \\
\hline 7 & 5206 & 4370 & 0.068 & 0.057 \\
\hline
\end{tabular}

Table 4. Distance Cost for Existing Location (EL), Optimal Location (OL) and Average Cost Per Incident for Nine Months (July 2016 to March 2017)

\begin{tabular}{|l|l|l|l|l|l|}
\hline Number of Facilities & EL Cost & OL Cost & $\begin{array}{l}\text { Average } \\
\text { Distance Cost } \\
\text { for EL }\end{array}$ & $\begin{array}{l}\text { Average } \\
\text { Distance Cost } \\
\text { for OL }\end{array}$ & $\begin{array}{l}\text { Average Percentage } \\
\text { Cost Increase }\end{array}$ \\
\hline 2 & 855120 & 7106 & 11713.97 & 97.34 & 11934.08 \\
\hline 3 & 7600 & 6498 & 104.11 & 89.01 & 16.96 \\
\hline 4 & 6916 & 5928 & 94.78 & 81.21 & 16.70 \\
\hline 5 & 6308 & 5396 & 86.41 & 73.92 & 16.89 \\
\hline 6 & 5738 & 4864 & 78.60 & 66.63 & 17.96 \\
\hline 7 & 5206 & 4370 & 71.31 & 59.86 & 19.13 \\
\hline
\end{tabular}




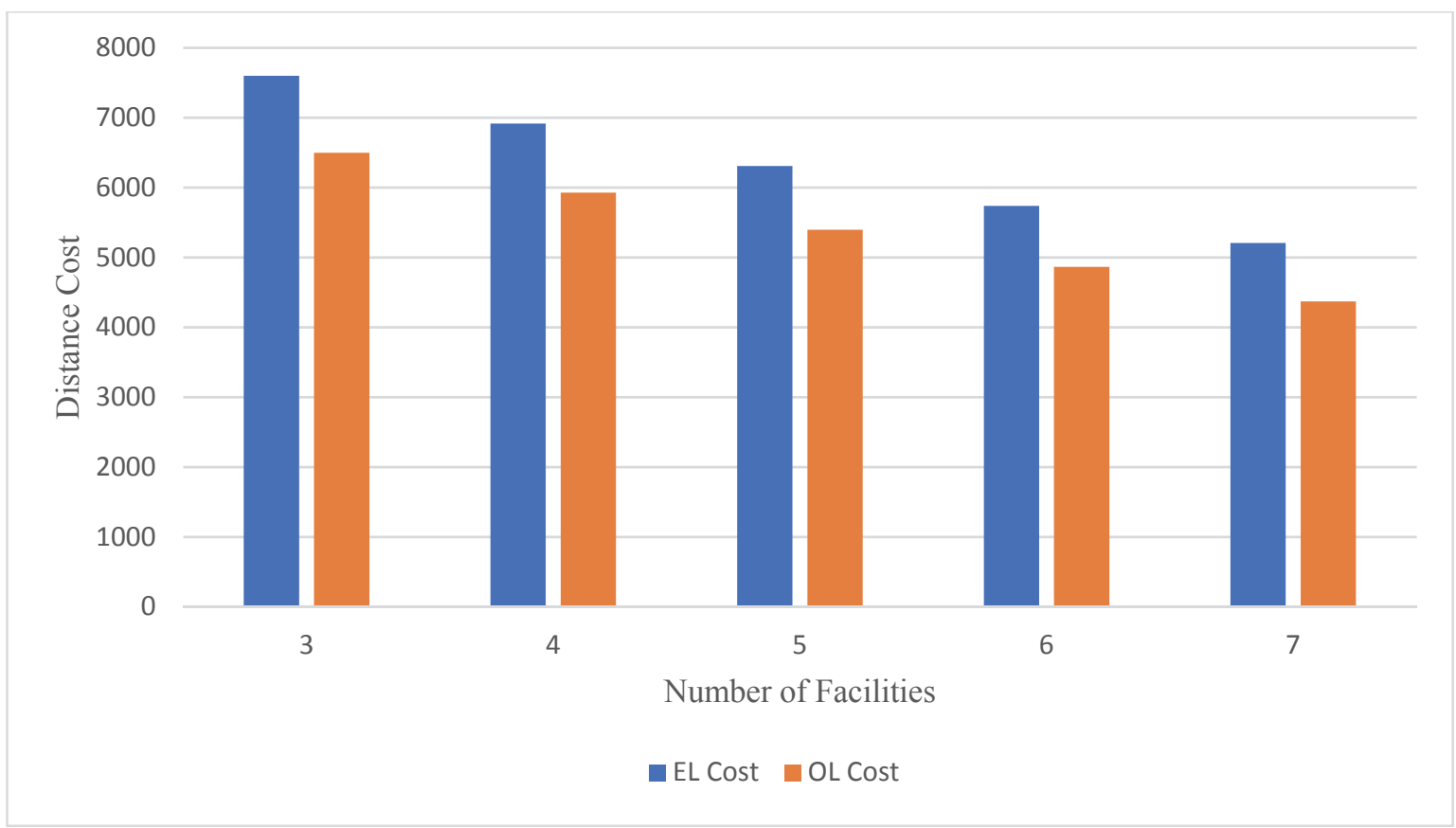

Figure 1. Distance Cost for Additional Existing Location (EL) and Optimal Location (OL)

Table 2 shows the existing and optimal locations when locating 2 to 7 ambulance stations. Currently, we have ambulance stations at node 1 (Mackay City) and node 4 (North Mackay). We located additional stations using the two existing stations as a constraint which should be in the final solution. In practice that is what happens when for example we have fixed facilities and we are expected to add new facilities to the existing ones. The TPWD for the two existing ambulance stations is 855120 and the optimal value is 7106 . Table 2 and Figure 1 show TPWD for 2 to 7 and 3 to 7 ambulance stations for the EL and OL respectively. The cost of using the existing location or the optimal location is the distance cost of accessing the facilities.

Tables 3 and 4 show the average distance cost per person and per incident for nine months (July 2016 to March 2017) respectively for EL and OL. The average distance cost for EL ranges from 0.068 to 11.241 and it ranges from 0.057 to 0.093 for OL. There have been 73 ambulance incidents from July 2016 to March 2017 in the Mackay region so the average distance cost per incident for EL ranges from 71.31 to 11,713.97. For OL the average distance cost per incident is from 59.86 to 97.34 .

We also have the percentage cost increase in Table 4 which shows that there will be cost saving of $11934.08 \%$ if the $p$-median problem is used to locate the two existing ambulance stations optimally. This shows that the current ambulance locations at node 1 and node 4 have been located non-optimally.

\section{CONCLUSION}

The study is to assess the ambulance stations in Mackay metropolitan area. The study shows that the existing ambulance stations have not been optimally located. There is a large difference between the two existing locations and the locations obtained from the $p$-median model. We have outlined the importance of distance minimization in the study using the $p$-median model.

The results showed that the current ambulance locations have been located non-optimally. Some of the consequences of non-optimal locations are the reduction in accessibility of facilities for the customers and an increase in the cost of running the facilities. This might also lead to most of the customers (demand) not being served in a reasonable time. The operations of ambulances can clearly be improved if facilities are located more optimally or if more facilities are constructed. Maybe the facilities are located non-optimally at Mackay City (node 1) and North Mackay (node 4) because of local demand, public opinion or political decision.

The projected distance costs when facilities are added to existing facilities optimally are also noted and it decreases as more facilities are added. For further studies it will be worthwhile to compare the results from the $p$-median problem with the $p$-centre and the covering problems and their variants. 
Dzator M. and J. Dzator, The Optimal Location of Ambulance Stations in a Regional Area

\section{REFERENCES}

Barnveld, T.C., Bhulai, S., and R.D Mei (2015). A dynamic ambulance management model for rural areas: Computing redeployment actions for relevant performance measures, Health Care Management Science, 20, 165-186.

Basko J. (2008). Rural EMS, http://www.emergencymedicine.pitt.edu/sites/default/files/Rural\%20EMS\% 20Systems.pdf

Berlin, G., C. Revelle, and J. Elzinga (1976). Determining ambulance-hospital locations for on-scene and hospital services, Environment and Planning A, 8, 553-561.

Caccetta, L. and M. Dzator (2001). Models for the location of emergency facilities, In Ghassemi, F., Whetton, P., Little, R. and M. Littleboy (eds) MODSIM 2001 International Congress on Modelling and Simulation. Modelling and Simulation Society of Australia and New Zealand, December 2001, pp. 21492154. ISBN: 0-867405252.

Caccetta, L. and M. Dzator (2005). Heuristics methods for locating emergency facilities, In Zerger, A. and Argent, R.M. (eds) MODSIM 2005 International Congress on Modelling and Simulation. Modelling and Simulation Society of Australia and New Zealand, December 2005, pp. 1744-1750. ISBN: 0-9758400-29.

Carson, Y. and R. Batta (1990). Locating an ambulance on Amherst campus of State University of New York at Buffalo, Interfaces, 20, 43-49.

Chanta, S., Mayorga, M. E., and L. A McLay, (2014). Improving emergency service in rural areas: a biobjective covering location model for ems systems. Annals of Operations Research, 221, 133-159.

Daberkow, S. and G. King (1977). Response time and the location of emergency medical facilities in rural areas: a case study. American Journal Agricultural Economics, 59 (3), 467-477.

Daskin, M.S. (1995). Network and Discrete Location: Models, Algorithms and Applications, John Wiley and Sons, Inc., 498 pp., New York.

Daskin, M. and K., Maas (2015). The p-median problem. In: Laporte, G., Nickel, S., da Gama, F.S. (Eds.), Location Science. Springer International Publishing, 21-45.

Dzator, M., and J. Dzator (2013). An effective heuristic for the $P$-median problem with application to ambulance location. Opsearch 50 (1), pp. 60-74.

Dzator M and Dzator JA. (2015). Effective method for locating facilities, In Weber, T., McPhee, M.J. and Anderssen, R.S. (eds) MODSIM2015, 21st International Congress on Modelling and Simulation. Modelling and Simulation Society of Australia and New Zealand, December 2015, pp. 57-63. ISBN: 9780-9872143-5-5.

Dzator, M. and J. Dzator (2016). Health emergency facilities and development: Locating facilities to serve people and development better, The Journal of Developing Areas 50, 131-142.

Goodman, D.C., E. Fisher, T.A. Strukel and C. Chang (1997). The distance to community medical care and the likelihood of hospitalization: is closer always better?, American Journal of Public Health, 1144 1150 .

Hakimi, S.L. (1964). Optimisation locations of switching centres and the absolute centres and medians of a graph, Operations Research, 12, 450-459.

Hamilton, L., L. Stockhausen and J. Grootjans (2010). Stress in Australian rural ambulance paramedics: It's more about the 'rural' than the 'paramedic', http://www.rrh.org.au

Lee, E., (2014). Designing Service Coverage and Measuring Accessibility and Serviceability of Rural and Small Urban Ambulance Systems, Systems, 2(1), 34-53.

Leeuwenburg, T. and J. Hall (2015). Tyranny of distance and rural prehospital care: Is there potential for a national rural responder network?, Emergency Medicine Australasia, 27, 481-484.

McAleer, W.E. and I.A. Naqvi (1994). The relocation of ambulance stations: A successful case study, European Journal of Operational Research, 75, 582-588.

Pyper, Z. and J.L. Paterson (2016). Fatigue and mental health in Australian rural and regional ambulance personnel, Emergency Medicine Australasia, 28, 62-66.

Queensland Ambulance Service, https://www.ambulance.qld.gov.au/docs/QAS-PPIs-2016-17-Third-Quarter1-January-to-31-March-2017.pdf

Queensland Ambulance Service Performance, https:/www.qao.qld.gov.au/reports-parliament/queenslandambulance-service-performance

Serra, D. and V. Marianov (1998). The $p$-median problem in a changing network: the case of Barcelona, Location Science, 6, 383-394.

Toloo S., G. FitzGerald, P. Aitken, J. Ting, V. Tippett and K. Chu (2011). Emergency health services: demand and service delivery models. Monograph 1: literature review and activity trends, Queensland University of Technology, 104pp. Brisbane.

Travelmate, http://www.travelmate.com.au/map/ 